\title{
Traducciones hispanas de libros de higiene franceses en los primeros cinco años del siglo XIX
}

\author{
Susana María Ramírez Martín \\ Universidad Complutense de Madrid \\ sm.ramirez@pdi.ucm.es
}

\begin{abstract}
Resumen: La higiene y la salud pública son temas que preocupan no solo a la medicina, sino también a la política. Desde el descubrimiento de la vacuna contra la viruela, se conoce que para la prevención de los contagios es necesaria la higiene. Con la llegada del siglo XIX, se comienza a traducir libros franceses con este tema. Bartolomé José Gallardo (1800) y Antonio Ballano (1803) traducen la obra de Jean Baptiste Pressavin; Luis María Mejía (1801) trasladará la obra de Étienne Tourtelle; Juan de Rivera y Céspedes (1801) se encarga de la obra de François-Emmanuel Foderé y Joaquín Serrano (1803) traducirá la obra de Étienne Louis Geoffroy.
\end{abstract}

Palabras clave: higiene; medicina preventiva; salud pública; traducción al español; publicaciones francesas.

\section{Hispanic translations of French hygiene books in the first five years of the 19th century}

Abstract: Hygiene and public health are issues that concern not only medicine, but also politics. It is known that since the discovery of the smallpox vaccine is known that hygiene is necessary to prevent contagion. With the advent of the nineteenth century, it started translating French books with this subject. Bartolomé José Gallardo (1800) and Antonio Ballano (1803) translate the work of Jean Baptiste Pressavin, Luis María Mejía (1801) will transfer the work of Etienne Tourtelle, Juan de Rivera y Céspedes (1801) is responsible for the work of François-Emmanuel Foderé and Joaquín Serrano (1803) translates the work of Louis Etienne Geoffroy.

Keywords: hygiene; preventive medicine; public Health; translation into Spanish; French publications.

\ Ramírez Martín, Susana María. 2016. "Traducciones hispanas de libros de higiene franceses en los primeros cinco años del siglo XIX". Quaderns de Filologia: Estudis Lingüístics XXI: 267-285. doi: 10.7203/qfilologia.21.9323 



\section{El marco conceptual de la higiene a finales del siglo XVIII $\mathrm{y}$ principios del siglo XIX}

La Higiene como disciplina da sus primeros pasos en el tránsito del siglo XVIII al siglo XIX. A lo largo del siglo XIX esta rama de la medicina se consolidará en el conjunto de los saberes médicos (Gutiérrez Rodilla, 2000: 58). Llama la atención que en los cinco primeros años del siglo XIX se traducen al español cuatro libros de origen francés. Como en otras ocasiones, el conocimiento médico viene acompañado de la lengua francesa. Bien porque el original se ha creado en francés o bien porque los traductores españoles utilizan una versión intermedia en este idioma para realizar su traducción ${ }^{1}$. Pero, ¿por qué se traducen esos libros de higiene y qué motiva a sus autores?

A lo largo del siglo XVIII se verifica una identificación entre salud pública e higiene. Poco a poco, los Estados ilustrados se consideran responsables de la higiene pública. Al mismo tiempo se establecen protocolos de control de la salud, propagando primero una policía médica y después una medicina forense. Para saber más sobre este tema véase la obra de Conde Naranjo (2007: 81). Este proceso natural y lógico no se hubiera realizado sin la formación de profesionales sanitarios en los colegios de Cirugía.

La higiene a principios del siglo XIX puede ser estudiada desde un contexto médico y desde un contexto sociopolítico; además, en este artículo se va a estudiar desde un contexto librario y documental.

\subsection{Contexto médico}

El desarrollo de la medicina y de la cirugía a lo largo de la Ilustración trae como consecuencia a finales del siglo XVIII una nueva valoración de la vida humana. Surgen en los Gobiernos el interés y la ocupación por la salud de sus súbditos con el fin de buscar una mayor utilidad y prosperidad social. En palabras de Pressavin (1819: XXX): "Aseguro que la higiene es la parte más segura y menos conjetural de la medi-

\footnotetext{
*Esta publicación se enmarca en el Proyecto GV2016-113 "Traductores del pasado" concedido por la Generalitat Valenciana.

1 "Este proceso colectivo, más o menos azaroso, selectivo y de innegable interés, supuso la puesta al día en castellano de la mejor bibliografía médica extranjera" (Riera Climent y Riera Palmero, 2007: 15).
} 
cina”. La higiene y la terapéutica tienen que ser incorporadas como elementos independientemente dentro del corpus médico ${ }^{2}$.

La higiene es una disciplina que se empieza a enseñar a médicos y cirujanos, al mismo tiempo que se da un desarrollo de la medicina preventiva para evitar el desarrollo de enfermedades contagiosas. La salud, además de ser una preocupación individual y personal, comienza a ser una cuestión colectiva y del grupo.

\subsection{Contexto sociopolítico}

La sanidad y los avances médicos, quirúrgicos y farmacéuticos del siglo XVIII favorecieron el crecimiento de la población.

Los profesionales de la medicina se enfrentan a dos situaciones complementarias según dónde se ponga el foco de atención. Por un lado, los médicos son escasos y, por otro, la población en general no puede acceder a ellos por cuestiones económicas. En consecuencia, estos libros pretenden, por una parte, dar pautas que facilitan el acceso a la salud para mayor parte de población y, por otra, ofrecer criterios de valoración al paciente para que pueda descubrir la buena y la mala praxis médica.

A lo largo del siglo XVIII se verifica una identificación entre salud pública e higiene. Poco a poco, los Estados ilustrados consideran la salud como algo que proteger y la medicina como la ciencia que hay que cultivar para esa protección.

\subsection{Contexto documental y librario}

Los sanitarios son escasos y los libros médicos intentan cubrir las necesidades de información que tiene la población lectora. Los libros médicos forman a los facultativos, pero también ilustran las ansias de conocimiento que sobre el tema médico se suscitan entre estos lectores.

A mediados del siglo XVIII, comienzan a imprimirse publicaciones relacionadas con la salud y su conservación. La preocupación por la salud fomentará las traducciones de obras médicas con una finalidad

\footnotetext{
2 "Para comodidad de los principiantes se explican los términos griegos y difíciles; se ponen notas para la inteligencia de muchos lugares; se declara la Hygiene y la Terapéutica, que se ponen en orden alfabético". Gazeta de Madrid, 11 noviembre de 1796, 22 de septiembre de 1797 y 25 de septiembre de 1798 .
} 
formativa y divulgativa. El aumento de la demanda alertará a los libreros, que incrementarán un mercado activo de este tipo de publicaciones. El libro médico será más valorado por ellos en la medida en que incrementa su negocio.

Los médicos demandan información sanitaria y quirúrgica. Aunque la formación en los colegios de Cirugía y Medicina es buena, el médico práctico necesita formación continua. Los médicos formados en España y pensionados por la Corona en Europa, descubren otra perspectiva de las prácticas médico-sanitarias que, a su vuelta, quieren difundir en España. Son necesarias las traducciones. Pero las traducciones de estas publicaciones médicas no siempre son realizadas por sanitarios. Estos traductores controlan la lengua de origen, pero les falta precisión en los conceptos utilizados.

Algunas son publicaciones que originariamente se habían escrito en latín y al español llegan desde traducciones intermedias francesas. En la mayoría de las ocasiones, las ideas médicas arriban a España con un gran retraso como consecuencia del desfase de tiempo en trasladar la información de un idioma a otro.

\section{Las obras, autores y traductores}

En los cinco primeros años del siglo XIX hemos identificado un conjunto de cuatro publicaciones de obras de higiene francesas traducidas al español.

\subsection{El arte de conservar la salud y prolongar la vida o Tratado de higiene (1800)}

La primera obra sobre higiene es la titulada El arte de conservar la salud y prolongar la vida o Tratado de higiene de Jean Baptiste Pressavin, que tradujo por primera vez al español José Bartolomé Gallardo (17761852) en 1800 y se publicó en la imprenta salmantina de Francisco Tomar. El original del Dr. Pressavin en francés, que se titulaba L'Art de prolonger la vie et de conserver la Santé, ou Traité de hygiène, se había publicado en Lyon en 1786 en la imprenta de Cuchet. Años más tarde, en 1804, se reimprime de nuevo la traducción de Gallardo en la imprenta madrileña de Mateo Repullés. La obra tuvo buena acogida en la población lectora española. 
La obra de Pressavin conservó sus características casi durante 20 años. Podemos afirmar que la traducción realizada por José Bartolomé Gallardo mantenía su vigencia en forma y contenido.

El libro es un compendio de higiene privada. Tiene poca originalidad y una marcada intención divulgadora. En la nota del traductor están bien definidos los objetivos que ha pretendido conseguir y qué método ha seguido para poner la obra en español.

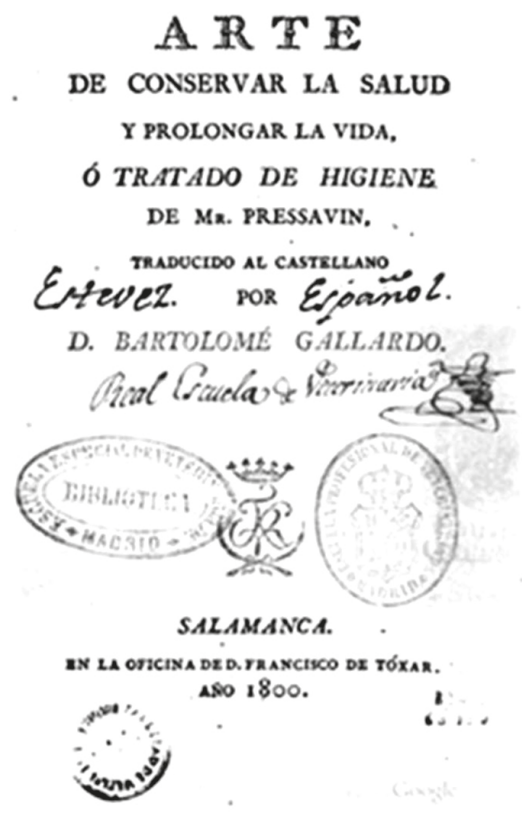

La traslación intenta mantener fiel la literalidad del texto francés. Así lo afirmaría Gallardo en el "Prólogo del Traductor" (Pressavin, 1819: XXXIV).

Al mismo tiempo, en la traducción Gallardo huyó de los tecnicismos médicos con el fin de facilitar la lectura y la divulgación de los contenidos. Como ejemplo dice que emplea "Aurículas del corazón en lugar de alas" (Pressavin, 1819: XXXIV-XXXV).

En las publicaciones en español, se diferencian las aportaciones traducidas de Pressavin del "contenido corregido y aumentado en las 
segunda edicion con varias notas y adiciones por un amante de las ciencias naturales con un asterisco $(*)^{n}$.

\subsubsection{Su autor: Jean Baptiste Pressavin (1734- ¿?)}

Nació en Beaujeu (Ródano) el 30 de marzo de 1734, en una familia de cirujanos. Estudió Cirugía en el Colegio de Médicos de esa ciudad. Llegó a ser profesor y desempeñó el cargo de archivero y conservador del Museo Anatómico. Se puso del lado de la Revolución a partir del año 1789. Durante la Convención fue elegido diputado por el Ródano y se comprometió con la República. En 1798 fue nombrado miembro del Consejo de los Quinientos por el Departamento del Ródano y estuvo en este cargo durante dos años. Después del 18 Brumario abandona la vida política. La fecha de su muerte se desconoce.

\subsubsection{Su traductor: Bartolomé José Gallardo (1776-1852)}

Bartolomé José Gallardo y Blanco nació en Campanario, provincia de Badajoz, el 13 de agosto de 1776 y murió en Alcoy, provincia de Alicante, el día 14 de septiembre de 1852. Fue hijo de campesinos. Estudió Filosofía en la Universidad de Salamanca. Allí descubrió a los enciclopedistas franceses y su idioma.

Gallardo solo contaba con 24 años cuando tradujo la obra del Dr. Pressavin en 1800. El éxito del libro le reconoció socialmente como conocedor de la lengua francesa. En 1803, traduce la obra de Jean Louis Alibert titulada Discurso sobre la conexión de la medicina con las ciencias físicas y morales, ó sobre los deberes y cualidades y conocimientos del médico en la misma editorial salmantina. En 1806 ya era catedrático de este idioma en el Real Colegio de Caballeros Pajes de su Majestad. Con la guerra de la Independencia, se traslada a Cádiz y allí, en 1811, fue nombrado bibliotecario de las Cortes. Para saber más sobre la figura de Bartolomé José Gallardo se puede consultar Gallego Lorenzo (2006: 227-237), Basanta Barro (1995: 35-51) y Simón Díaz (1995: 69-75).

\footnotetext{
3 "Los párrafos señalados con esta * son los que se han aumentado, entresacados ellos y las notas de demás adiciones de las obras corrientes del día” (Pressavin, 1819: IV).
} 
Gallardo conoce el idioma, pero no tiene una formación como médico. Le ayuda en la traducción Antonio Ballano, que es médico del Hospital General, censor en la Real Academia de la Medicina de Madrid y profesor en el Real Estudio de Medicina Práctica de la Corte. Para evitar problemas con la censura y facilitar la publicación y la reimpresión, será el Dr. Ballano quien solicite estas licencias en calidad de anotador de la obra ${ }^{4}$.

Además de la traducción de la obra de Pressavin elaboró un diccionario de medicina y cirugía de siete volúmenes y un elogio fúnebre ${ }^{5}$ dedicado a José Severo López ${ }^{6}$, presidente de la Real Academia de la Medicina

\subsection{Elementos de Higiene ó del influxo de las cosas físicas y morales en el Hombre y medios de conservar la salud (1801-1806)}

La obra vió la luz en francés por primera vez en el V año de la República (1796-1797) con el título Éléments d'hygiène: ou de l'influence des choses physiques et morales sur l'homme et des moyens de conserver la santé. Se publicó en dos tomos en París, en la imprenta de Levrault, y en Estrasburgo, en la imprenta de Teófilo Barrois. Tourtelle mejora la obra y la publica en la misma imprenta parisina, con el mismo título en 1802. La traducción en la Península Ibérica de la obra de Tourtelle se realizó desde la primera edición francesa. Esta traducción se publicó un año antes de la segunda edición en francés en la imprenta de Benito Cano en dos tomos.

Elementos de Higiene ó del influxo de las cosas físicas y morales en el Hombre, y medios de conservar la salud, escritos en Francés por el ciudadano Estevan Tourtella, profesor de la escuela de la salud de Strasbourg. Extractados y traducidos al castellano con algunas notas

\footnotetext{
${ }^{4}$ Licencia concedida el 19 de abril de 1804 para la reimpresión de la obra Arte de conservar la salud y prolongar la vida o tratado de higiene de Jean Baptiste Pressavin solicitada por su traductor del francés y anotador Antonio Ballano. Archivo Histórico Nacional (AHN), Consejos, 5566, Exp. 39.

${ }^{5}$ Licencia concedida el 25 de junio de 1808 para impresión de la obra Oración fúnebre predicada en las exequias que se celebraron por el difunto José Severo López solicitada por su autor. AHN, Consejos, 5569, Exp. 16.

${ }^{6}$ José Severo López fue médico de Cámara y catedrático del Real establecimiento de Clínica, nació en Madrid el 8 de setiembre de 1754 y murió el 12 de diciembre de 1807.
} 
por don Luis María Mejía profesor de Cirugía de esta Corte fue una obra dirigida a un público lector muy amplio. "Es obra útil a los eruditos, y á todas las personas que quieran conservar su salud"7.

Esta obra es muy útil no solo a los profesores de cirugía y medicina, sino a toda clase de personas que quieran instruirse en su conservación ${ }^{8}$.

\section{3}

- ELEMENTOS DE HYGIENE

O DEL INFLUXo 72

DE LAS COSAS FISICAS Y MORALES

EN EL HOMBRE,

× yedios de cosservar ia salud.

MSCRITOS EN SRAMCES

OQR RL CIVDADANO RSTEVAN TOURTELLT

profesor de la escuela de la salú

de Strasbourg.

EXTRACTADOS Y TRADUCIDOS AL CASTELIANO

CON ALOUNAS NOTAS

TOR DON LUIS MAR'A $M \mathrm{BXIA,}$

profesor de Cirugfa de esta Corte.

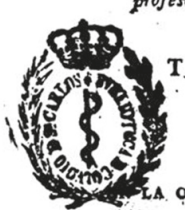

TOMO PRIMERO.

CON LICENCIA

OFICINA DE DON BENITO CANO.

Aks DE 1801.

Los dos tomos se publicaron mediante suscripción. La del primer tomo se inició en el verano de 1800 y se puso a la venta en marzo del año siguiente. Se distribuyó en tres librerías madrileñas: la de Quiroga, que tenía dos sedes, una en la calle Concepción y otra en Carretas, la de Castillo y la de Alonso, que estaban frente a las gradas de la Iglesia de San Vicente el Real. El coste del primer tomo fue de ocho reales en rústica y 12 en pasta. El precio del segundo volumen se incrementó en rústica dos reales y mantuvo el mismo precio en pasta.

\footnotetext{
${ }^{7}$ Gazeta de Madrid n. ${ }^{\circ}$ 18, de 3 de marzo de 1801.

${ }^{8}$ Gazeta de Madrid n. ${ }^{\circ}$ 64, de 12 de agosto de 1800.
} 
La obra Elementos de Higiene ó del influxo de las cosas físicas y morales en el Hombre, y medios de conservar la salud está concebida en dos volúmenes, que a su vez se dividen en seis secciones, con capítulos. La primera sección se dedica a la vida, la salud, las fuerzas vivificadoras (ocho capítulos). La segunda sección se dedica al hombre en relación con las cosas que le rodean y las cosas que se aplican a la superficie del cuerpo (siete capítulos). La tercera sección se dedica a las necesidades alimenticias, a los tipos de alimentos y su preparación (diez capítulos). En la cuarta sección, se abordan los temas del movimiento / reposo y sueño / vigilia (tres capítulos). Y en la sexta sección se analiza la influencia recíproca de lo físico en lo moral y viceversa (seis capítulos).

El contenido de esta publicación responde a los temas del Curso de Higiene que impartía Tourtelle en la Universidad. En ella se sistematiza el contenido de esta disciplina y se le considera un pionero en ello. Esta publicación es necesaria para la época, además llena un vacío y satisface una necesidad. Solo por esta obra, este autor es reconocido por un pionero de la higiene. La traducción de Mejía llegó a figurar como libro de texto recomendado a los colegiales del Real Colegio de San Carlos en Madrid y es uno de los más solicitados en el contexto de la medicina hispana (Gómez de Enterría, 2013: 289).

\subsubsection{Su autor: Étienne Tourtelle (1756-1801)}

Nació en Besançon el 17 de febrero de 1756. A los catorce años acabó sus cursos de Filosofía. Luego estudió con el cirujano Morel. Por las mañanas acompañaba la visita de enfermos en el hospital y realizaba muy bien los informes. Sus padres le obligaron a entrar en un convento de dominicos, que pronto abandonó y se trasladó a Montpellier. Su talante algo bohemio le llevó a París para continuar sus estudios.

En 1787 ganó la oposición de profesor de Medicina de Besançon. La Revolución francesa suprimió este centro universitario. Él aceptó una plaza de médico en la Armada del Rhin. La recién creada Escuela de Medicina de Estrasburgo le llamó para impartir docencia, pero estuvo poco tiempo debido a las condiciones de frío y humedad de su clima.

Volvió a Besançon, donde empezó a trabajar como médico en el Hospital Militar. Enfermo de los bronquios, tenía tos persistente y la primavera empeoraba su cuadro alérgico. Murió el 17 de mayo de 1801 a los 45 años, rodeado de su mujer y sus seis hijos (Quantin, 1862). 


\subsubsection{Su traductor: Luis María Mejía}

Sobre la biografía de Luis María Mejía solo sabemos los datos que se traslucen en los libros que tradujo y en la propaganda de estos. Trabajó como practicante de cirugía en los hospitales de Madrid y después ejerció la oftalmología en Valladolid (Riera Palmero, 1972: 41-61).

La obra del Dr. Tourtelle es traducida por Luis María Mejía, cirujano de la Corte ${ }^{9}$. El traductor solicita al Conde de Isla licencia de impresión de la obra de Tourtelle titulada Elementos de Higiene, el 15 de diciembre de $1801^{10}$. Los encargados de censurar la obra fueron Juan Manuel Pérez y Juan Bautista Soldevilla. Dieron su dictamen el 14 de septiembre de $1802^{11}$. El traductor no se convence hasta que finalmente, en enero de 1804, al dictamen le acompaña una lista de errores encontra$\operatorname{dos}^{12}$. Esta obra en 1828 fue traducida para uso docente por José Félix Merizalde (Ramírez Martín y Domínguez Ortega, 2016).

\subsection{Leyes ilustradas por las ciencias fisicas o Tratado de medicina legal y de higiene pública (1801-1803)}

Esta obra de Foderé, titulada Les lois éclairées par les sciences physiques, ou Traité de Médecine legale et d'Hygiène publique, se publica en tres volúmenes en 1799. Desde 1801 a 1803, fue traducida al español por Juan de Rivera y Céspedes con el título Las leyes ilustradas por las ciencias físicas o Tratado de medicina legal y de higiene pública.

La obra de Foderé cuenta con el apoyo del Dr. Hallé, profesor de Higiene, según aparece en la Advertencia de la traducción de Juan de Rivera y Céspedes cuando afirma que "su censura influyó en el plan de la obra y se imprimió esta por recomendación suya" (1801: I, XI). El Tratado de medicina legal y de higiene pública o de policía sanitaria

\footnotetext{
${ }^{9}$ Gazeta de Madrid n. ${ }^{\circ} 85$, de 17 de octubre de 1806.

${ }^{10}$ Carta de Luis María Mejía dirigida al Conde de Isla, fechada en Madrid el 15 de diciembre de 1801. Archivo de la Real Academia Nacional de Medicina (ARANM), Manuscritos siglo XVIII, Leg. 17, doc. 953.

${ }^{11}$ Dictamen de Juan Bautista Soldevilla y Juan Manuel Pérez, sobre la traducción de Luis Mejía de la obra de Tourtelle, Elementos de Higiene, fechado en Madrid el 14 de septiembre de 1802. ARANM, Manuscritos siglo XVIII, Leg. 14, doc. 768.

${ }^{12}$ Lista de errores encontrados por Juan Manuel Pérez y Juan Bautista Soldevilla en la traducción de Luis Mejía de la obra Elementos de Higiene de Tourtelle. ARANM, Manuscritos siglo XVIII, Leg. 17, doc. 760.
} 
tuvo una primera edición en francés que fue publicada en 1798, y una segunda en 1813. Constituye el manual de jurisprudencia médica de casi toda Europa durante los primeros años del siglo XIX. El propio autor reconoce la novedad de la obra aunque no en el contenido, sino en su sistematización.

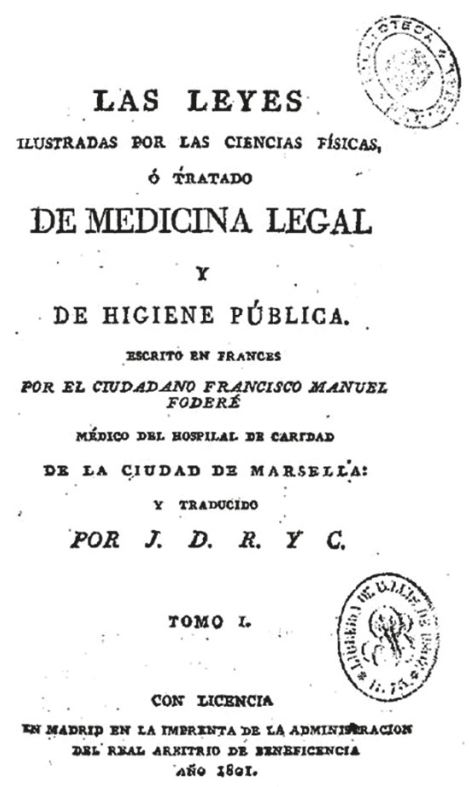

(c) Biblioteca Nacional de España

La obra de Francisco Manuel Foderé y la traducción de Juan de Rivera y Céspedes enseguida contaron con detractores que generaron polémica. Este es el caso de Higinio Antonio Lorente ${ }^{13}$, que en 1802 escribió cinco volúmenes criticando al Dr. Foderé, que publicó en dos imprentas públicas: la de la Administración del Real Arbitrio de Beneficencia y la imprenta Real. El Dr. Lorente, a finales del siglo XVIII, había traducido otra obra sobre el mismo tema, que había escrito el médico

\footnotetext{
${ }^{13}$ Higinio Antonio Lorente era médico de número en el Hospital de la Pasión de Madrid. En 1798 fue nombrado médico de la Cámara de Carlos IV, y destituido del mismo nombramiento por Fernando VII en 1823.
} 
austro-húngaro José Jacobo von Pleck (1738-1807) en Viena en 1781 y que se tituló en español: Medicina y cirugía forense ó legal. Esos conocimientos previos le hacen cuestionar el contenido de la obra de Foderé.

Pero la polémica no se termina aquí. Otro médico, Francisco Bonafón ${ }^{14}$, cuestiona la crítica realizada por el Dr. Lorente y publica un folleto de réplica titulado Carta Primera escrita por D. Francisco Bonafón al Doctor D. Higinio Antonio Lorente en respuesta al primer folleto que ha publicado baxo el título Errores médico-legales cometidos por Francisco Manuel Foderé en su obra Las Leyes ilustradas por las ciencias físicas, ó Tratado de Medicina legal y de Higiene Pública, que se publica en la imprenta Real en 1802.

Esta obra se imprimió a demanda ${ }^{15}$; por suscripción. Los cinco volúmenes exigían una inversión económica. Su precio en pasta era de trece reales y en rústica tres reales más barato. Inicialmente, quienes se encargaron de su venta fueron las librerías madrileñas de Castillo, que estaba situada frente a las gradas de San Vicente, y la de Escribano, que estaba ubicada en la calle Carretas. A partir del cuarto volumen la distribución y venta se hizo en la librería de Antonio Calleja, que estaba situada en la calle de Majaderitos ${ }^{16}$. Esta librería no solo se encargó de la venta de la traducción de Céspedes sino de la obra crítica de Lorente ${ }^{17}$.

Como hemos visto, la obra de Foderé llega a España muy tardíamente porque el espacio bibliográfico lo llenaba otra obra de higiene: la de Domingo Vidal Abad (1741-1800) ${ }^{18}$. Esta obra, que se titulaba Cirugía forense o Arte de hacer las relaciones chirurgico-legales/obra util a los médicos, cirujanos y jurisperitos, tuvo gran repercusión porque se utilizó como libro de formación de cirujanos en los colegios de Cirugía. Se publicó por primera vez en Barcelona en 1783, y en 1802 ya tenía cuatro ediciones.

\footnotetext{
${ }^{14}$ Antonio Bonafón era médico y profesor de Medicina en el Real Colegio de Madrid.

15 "Esta obra constará de tantos cuadernos quantos sean los tomos de la traducción, y para mayor comodidad de los que tengan esta, y que puedan colocarlos en los tomos respectivos; se ha procurado salgan del mismo tamaño y letra". Gazeta de Madrid n. ${ }^{\circ} 28$, de 6 de abril de 1802.

${ }^{16}$ Gazeta de Madrid n. ${ }^{\circ} 10$, de 4 de febrero de 1803.

${ }^{17}$ Gazeta de Madrid n. ${ }^{\circ}$ 70, de 27 de agosto de 1802.

${ }^{18}$ Desde 1775, Domingo Vidal Abad fue bibliotecario del Colegio de Cirugía de Barcelona y a partir de 1786 imparte docencia. En 1796 se traslada a Cádiz en calidad de subdirector del Colegio de Cirugía de Cádiz y fallece en la epidemia de fiebre amarilla que asola Cádiz en 1800.
} 


\subsubsection{Su autor: François Emmanuel Foderé (1764-1835)}

El saboyano Foderé fue médico de Carlos IV y de Fernando VII durante su estancia en Francia. Al primero le atendió en Marsella y al segundo durante una convalecencia en Valençay. Impartió docencia en la cátedra de Medicina Legal en Estrasburgo.

Francisco Manuel Foderé nació en San Juan de Maurienne, en la Saboya, el 8 de enero de 1764. Estudió en Turín y cuando decide seguir la carrera médica, en 1787, se traslada a París. Al terminar sus estudios en París se marcha a Inglaterra y vuelve a su patria en 1790.

Desde entonces los destinos de Foderé le ligaron a España. Primero estuvo agregado al ejército de Italia en calidad de médico. Cuando llegó a Marsella con el cuerpo de tropas al mando del general Carteaux, se casó con la hija mayor de Mr Moulard, médico del hospital de aquella ciudad. Pocos días después Bernadotte y José Bonaparte casaron con las hermanas Clary, que eran primas hermanas de la esposa de Foderé.

Fue nombrado miembro de la Junta de Sanidad de los Altos Alpes. En el año VII de la República publicó su Tratado de medicina legal, que fue su verdadero título de gloria, y le aseguró la inmortalidad. Ejerció como profesor de Física y de Química en la Escuela Central de Niza, de la que fue nombrado director. En 1799 era médico del Hospital de Caridad de la ciudad de Marsella.

Cuando el Rey de España, Carlos IV, llegó enfermo a Marsella, sabedor de la alta reputación de Foderé, le envió a llamar y le eligió por su médico consultor. Más adelante, y cuando los príncipes españoles, prisioneros en Valençay, solicitaron del Gobierno francés el favor de tener por médico al que había salvado la vida a su padre, se autorizó a Foderé para que residiese cerca de ellos. Foderé estuvo entre un rey sin corona y los intereses de su primo, que exigía información del prisionero de Valençay. A pesar del afecto que Foderé profesaba a los príncipes cautivos, su permanencia en Valençay no debía convenir a su carácter. Continuamente interrogado por los agentes de una policía recelosa, solicitó y obtuvo a principios de 1813 el permiso de separarse de los príncipes.

Cuando en 1814 se crea en Estrasburgo la cátedra de Medicina Legal, es elegido por unanimidad para ocuparla. Foderé murió en esa ciudad el 4 de febrero de 1835 a los 71 años de edad. 


\subsubsection{Su traductor: Juan de Rivera y Céspedes ${ }^{19}$}

Esta obra no fue traducida por un sanitario. Es oficial de la Secretaría de Cruzada $^{20}$. Poco más sabemos de su vida. Juan de Rivera y Céspedes traduce esta obra médica sin conocer su contenido. La traducción de Rivera y Céspedes tiene la ayuda del sanitario Antonio Bonafón (Foderé, 1801: I, VIII).

Esta obra de Foderé entretuvo bastante tiempo a los académicos. El 15 de marzo de 1802 la Academia acuerda sobre la censura de la obra Errores médicos legales cometidos por el ciudadano Foderé ${ }^{21}$. Esta preocupación de la Academia nace por una nota que Higinio Antonio Lorente les había enviado el día anterior ${ }^{22}$. Los censores fueron Antonio Franseri y Miguel Barnades ${ }^{23}$, pero antes de emitir el dictamen de censura remiten al Conde de Isla los manuscritos para que los revise ${ }^{24}$.

Ante la disputa que está generando su obra, el mismo Foderé escribe una carta en latín a la Academia en la que da su parecer ${ }^{25}$ y otra con la misma fecha en la que agradece a Casimiro Gómez Ortega su nombramiento como socio correspondiente ${ }^{26}$.

\footnotetext{
${ }^{19}$ El apellido Rivera se utiliza indistintamente con "v" y con "b". He preferido el uso de "v" porque es el utilizado en la firma de solicitud de licencia de traducción.

${ }^{20}$ Este dato se sabe gracias al expediente que se instruye para la solicitud de matrimonio de Juan de Rivera Céspedes con María Francisca Piferrer Garriga. AHN, Fondos Contemporáneos del $\mathrm{M}^{\mathrm{o}}$ de Hacienda, 513, Exp. 2603.

${ }^{21}$ Acuerdo de la Academia sobre la censura de la obra Errores médicos legales cometidos por el ciudadano Foderé, fechado en Madrid el 15 de marzo de 1802. ARANM, Manuscritos siglo XVIII, Leg. 13, doc. 738.

${ }^{22}$ Nota de Higinio Antonio Lorente sobre la impugnación de la Medicina Legal de Foderé. ARANM, Manuscritos siglo XVIII, Leg. 13, doc. 745.

${ }^{23}$ Dictamen de Antonio Franseri y Miguel Barnades sobre los Errores médico legales cometidos por el ciudadano Foderé en su tratado de Medicina legal, fechado en Madrid el 25 de noviembre de 1802. ARANM, Manuscritos siglo XVIII, Leg. 14, doc. 772.

${ }^{24}$ Envío del Conde de Isla a Miguel Barnades de los cuadernos $4^{\circ}$ y $5^{\circ}$ de Errores médico legales cometidos por el ciudadano Francisco Manuel Foderé. ARANM, Manuscritos siglo XVIII, Leg. 14, doc. 788.

${ }^{25}$ Carta de Foderé, fechada el 24 de mayo de 1807. ARANM, Manuscritos siglo XVIII, Leg. 15, doc. 855.

${ }^{26}$ Carta de Foderé dirigida a Casimiro Gómez Ortega agradeciendo el nombramiento de socio de la ARANM, fechada en Martiques el 24 de mayo de 1807. ARANM, Manuscritos siglo XVIII, Leg. 15, doc. 869.
} 


\subsection{La higiene o el arte de conservar la salud (1803)}

La obra del biólogo y farmacéutico francés Esteban Luis Geoffroy (1725-1810) es la cuarta obra sobre higiene que se traduce al español. En 1771, la obra de Geoffroy se había publicado en París en latín con el título Hygieine sive ars sanitatem conservandi poema. El 23 de agosto de 1771 la obra recibe la licencia de impresión por Vernage. Tres años más tarde, en 1774, M. de Launay tradujo del latín al francés la obra de Geoffroy.

Esta traducción francesa que se tituló L'hygiene ou L'art de conserver la santé: poëme latin es la que llega a España. Será Joaquín Serrano Manzano el responsable de su traducción al español. La obra, que se publicó en 1803 en la imprenta Real, se tituló La higiene o el arte de conservar la salud: poema latino. En la propaganda que se hace en la Gazeta de Madrid se dice que este poema "se puede tener por un código de medicina preservativa" 27 .

Esta traducción se vendía en la librería de Castillo frente a las gradas de San Felipe el Real y en la librería de la viuda de Cerro en la calle de Alcalá, frente al Buen-Suceso. El precio era de 13 reales en rústica y no se imprimió en pasta ${ }^{28}$.

\subsubsection{Su autor: Étienne-Louis Geoffroy (1725-1810)}

E1 Dr. Geoffroy nació en una familia de médicos en París el 12 de octubre de 1725 y murió el 12 de agosto de 1810 en Soissons. Además de médico y farmacéutico, se dedicó a la entomología. Fue miembro de la Real Academia de Ciencias de Francia y Regente de la Facultad de Medicina de la Universidad de París.

Desde su publicación, su obra fue muy estimada por sus contemporáneos (Flourens, 1852: 28).

\subsubsection{Su traductor: Joaquín Serrano Manzano}

Pocas noticias biográficas hay sobre Joaquín Serrano Manzano. Sabemos que tradujo libros médicos del inglés, del francés y del italiano.

\footnotetext{
${ }^{27}$ Gazeta de Madrid n. ${ }^{\circ}$ 65, de 16 de agosto de 1803.

${ }^{28}$ Gazeta de Madrid n. ${ }^{\circ}$ 65, de 16 de agosto de 1803.
} 
Fue secretario perpetuo del Real Colegio de Medicina de Madrid y del Real Estudio de Medicina Práctica.

Por su traducción de la obra de Geoffroy recibió fuertes críticas. La principal le llegó en 1804 desde el periódico Memorial literario o Biblioteca Periódica de Ciencias y Artes, en un análisis literario vejatorio titulado Carta de Taranilla a un amigo suyo, sobre la traducción que ha publicado de la Higiene de Geoffroy.

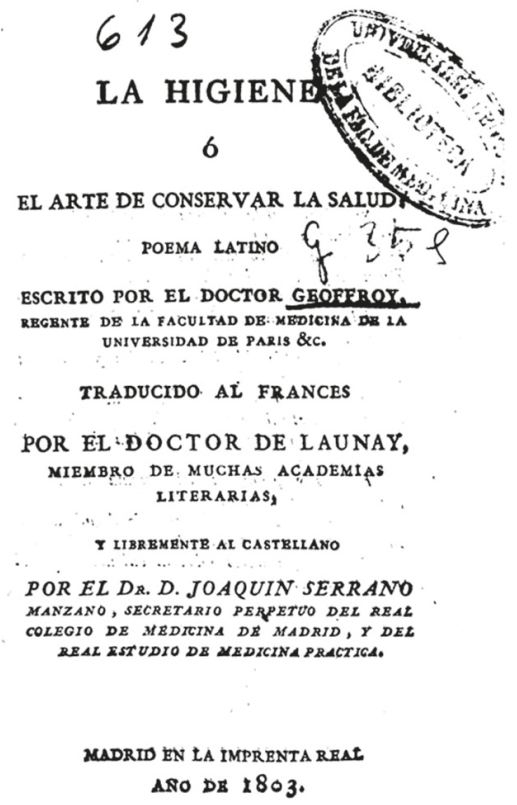

\section{A modo de conclusión}

Se puede afirmar que en los primeros años del siglo XIX las publicaciones de libros sobre higiene provenían de territorios de habla francesa y que hasta el año 1808 no se publicó un libro en español de pequeño formato sobre el tema, aunque se preocupara especialmente del ámbito militar. Vio la luz en la madrileña imprenta de Villalpando y se tituló Higiene militar ó Arte de conservar la salud del soldado en todas sus situaciones en mar y tierra: sacada de los autores mas clasicos. 
Las publicaciones analizadas se habían escrito originalmente en latín. Al español llegan desde traducciones intermedias francesas. El proceso es el mismo, aunque en diferentes momentos. Este desfase temporal entre la publicación y la traducción provoca que las ideas que llegan estén algo anticuadas y se tienen que actualizar para que el libro tenga vigencia.

Las publicaciones en español no estuvieron exentas de polémica. Ya en algunas de las advertencias de los editores se reconoce el atraso de las obras que se publican.

Además de las demandas terminológicas de otro lenguaje, el traductor tenía las exigencias del contenido material de los saberes y su vigencia en el momento de su traducción al español. Era frecuente que las traducciones enriqueciesen la obra original con notas explicativas del contenido traducido.

La mayoría de las traducciones están motivadas por un interés pedagógico. Además de los propios alumnos y de los profesionales, entre los destinatarios está contemplado el público en general.

Los traductores no necesariamente tienen que ser médicos. Los traductores de finales del siglo XVIII y de principios del siglo XIX proyectan una dimensión pedagógica en sus obras. Las obras traducidas saltan a América en versiones originales francesas y/o traducidas al español.

\section{Bibliografía}

Basanta Barro, José María. 1995. Bartolomé José Gallardo. Vida y obra. En Actas I Jornadas Bibliográficas Bartolomé J. Gallardo. Campanario: Centro de Estudios Gallardianos/Instituto de Enseñanza Secundaria "Bartolomé José Gallardo", 35-51.

Conde Naranjo, Esteban. 2007. La medicina de Estado. HID 33: 81-98. doi: https://dialnet.unirioja.es/servlet/articulo?codigo $=3234117$.

Corbella, Jacinto. 1995. Antecedentes históricos de la medicina legal en España. Barcelona: PPU.

Flourens, M. 1852. Élogie Historique d'Étienne Geoffroy Saint-Hilaire. Paris: Typographie de Firmin Didot.

Foderé François-Emmanuel. 1801-1803. Las leyes ilustradas por las ciencias fisicas ó Tratado de medicina legal y de higiene pública. Madrid: en la imprenta de la Administracion del Real Arbitrio de Beneficencia/en la Imprenta Real, 8 vols. 
Gallego Lorenzo, Josefa. 2006. Apuntes biográficos y bibliográficos sobre la figura de D. Bartolomé José Gallardo. Estudios Humanísticos. Historia 5: 227-237.

Gómez de Enterría, Josefa. 2013. Higiene y salud en las traducciones médicas del francés al español durante el siglo XVIII. Panace@ XIV (38). doi: http://www.medtrad.org/panacea/IndiceGeneral/n38-tribuna_GomezEJ.pdf.

Gutiérrez Rodilla, Bertha M. 2000. La higiene en la lexicografía médica de divulgación en la España decimonónica. Áreas. Revista Internacional de Ciencias Sociales 20: 51-60. doi: http://revistas.um.es/areas/article/ view/144651/129591.

Ramírez Martín, Susana María \& Domínguez Ortega, Montserrat. 2016. José Félix Merizalde ideólogo independentista y traductor de obra médica. Comunicación presentada en el Congreso Internacional de Americanistas, sin publicar.

Riera Palmero, Juan. 1972. Médicos Vallisoletanos. Salamanca: Seminario de Historia de la Medicina Española.

Riera Climent, Cristina \& Juan Riera Palmero. 2007. Libros, médicos y traductores en España (1850-1900). Zaragoza: Universidad de Zaragoza.

Simón Díaz, José. 1995. Don Bartolomé José Gallardo, Bibliógrafo. En Actas I Jornadas Bibliográficas Bartolomé J. Gallardo. Campanario: Centro de Estudios Gallardianos - Instituto de Enseñanza Secundaria "Bartolomé José Gallardo", 69-75.

Pressavin, Jean Baptiste. 1819. Arte de conservar la salud y prolongar la vida, $o$ Tratado de Higiene. Madrid: Imp. de Fermín Villalpando.

Quantin, Émile. 1862. Biographie de Étienne Tourtelle, Mémoire couronné au Concours de 1862 de la Société d'agriculture, Sciences et Arts de Poligny (Jura). Paris: Tipographie de Walder. 
